\title{
Overexpression of PCBP2 contributes to poor prognosis and enhanced cell growth in human hepatocellular carcinoma
}

\author{
XIUBING ZHANG ${ }^{*}$, LU HUA ${ }^{2,3^{*}}$, DALIANG YAN ${ }^{2}$, FENGBO ZHAO $^{4}$, JINXIA LIU ${ }^{2}$, HUILING ZHOU $^{2}$, JIE LIU $^{2}$, \\ MIAOMIAO WU ${ }^{2}$, CHENGLIANG ZHANG ${ }^{2}$, YINGYING CHEN ${ }^{2}$, BUYOU CHEN $^{3}$ and BAOYING HU ${ }^{4}$ \\ ${ }^{1}$ Department of Oncology, Nantong Second People's Hospital; ${ }^{2}$ Jiangsu Province Key Laboratory for Inflammation and \\ Molecular Drug Target, Nantong University; ${ }^{3}$ Department of Radiotherapy, Affiliated Hospital of Nantong University; \\ ${ }^{4}$ Basic Medical Research Centre, Medical College, Nantong University, Nantong, Jiangsu 226001, P.R. China
}

Received April 25, 2016; Accepted June 6, 2016

DOI: $10.3892 /$ or.2016.5167

\begin{abstract}
Poly(C)-binding protein 2 (PCBP2) is a member of the PCBP family, and plays an important role in post-transcriptional and translational regulation of various signaling molecules through direct binding to single-stranded poly $(\mathrm{C})$ motifs. PCBP2 has been reported to play a critical role in the development of multiple human tumors. However, whether PCBP2 participates in hepatocellular carcinoma (HCC) development remains largely elusive. Herein, we showed that PCBP2 was upregulated in human HCC tissues and cell lines. Overexpression of $\mathrm{PCBP} 2$ predicted significantly worsened prognosis in $\mathrm{HCC}$ patients, suggesting that $\mathrm{PCBP} 2$ may serve as a prognostic marker of HCC. In addition, we found that depletion of PCBP2 inhibited HCC cell proliferation, accompanying the increase in the cyclin-dependent kinase inhibitor p27 level. Moreover, we found that high expression of PCBP2 may contribute to sorafenib resistance in HCC cells, involving dysregulated expression of Bax and $\mathrm{Bcl}-2$ proteins. In conclusion, our results suggest that $\mathrm{PCBP} 2$ may serve as a prognostic marker and potential therapeutic target of HCC.
\end{abstract}

\section{Introduction}

Hepatocellular carcinoma (HCC) represents the third leading cause of cancer-related death worldwide and its incidence has been continuously increasing in the past several decades (1).

Correspondence to: Professor Buyou Chen, Department of Radiotherapy, Affiliated Hospital of Nantong University, 20 Xisi Road, Nantong, Jiangsu 226001, P.R. China

E-mail: chenbuyou1954@163.com

Mrs. Baoying Hu, Basic Medical Research Centre, Medical College, Nantong University, 19 Qixiu Road, Chong Chuan District, Nantong, Jiangsu 226001, P.R. China

E-mail: hubaoying12@163.com

${ }^{*}$ Contributed equally

Key words: poly(C)-binding protein 2, hepatocellular carcinoma, prognosis, cell proliferation, sorafenib resistance
Due to delayed diagnosis and high prevalence of HCC invasion and metastasis, the 5-year postoperative survival rate of HCC is only $30-40 \%$ (2). Presently, although many different treatments including surgery and chemotherapy have been widely used, the therapeutic effect on patients with HCC is still limited (3) and the detailed pathological processes underlying HCC occurrence and development remain poorly understood (4). Therefore, it is urgent to clarify the molecular mechanisms of HCC development, and apply them to develop new strategies for therapy to improve HCC patient overall survival.

The poly(C)-binding proteins (PCBPs) are characterized by their high affinities and sequence-specific interactions with polycytosine. The PCBP family has central roles in transcriptional and translational regulation, including mRNA stabilization, translational silencing and translational enhancement (5-7). Through these function, it has been proven that PCBPs play an important role in the development and processes of tumors, including apoptosis (8), proliferation (9), invasion (10) and epithelial-mesenchymal transition (EMT) (11). However, the physiological significance of PCBPs in the generation and development of HCC has received less intensive attention.

PCBP2, belonging to the PCBP family, is one of the least studied protein in human cancers among the PCBPs. Most of the studies on PCBP2 have focused on its post-transcriptional and translational controls in RNA viruses $(12,13)$. Recently, the carcinogenic effect of PCBP2 has attracted research attention and some discoveries have revealed that PCBP2 may participate in the development of human tumors. For example, Molinaro et al showed that 2',5'-oligoadenylate synthetase (OAS) activation may occur in prostate cancer cells in vivo when stimulated by cellular mRNAs for PCBP2 (14). In human glioma, PCBP2 is overexpressed in tumor tissues and predicts adverse survival. It has been reported to promote glioma cell growth, migration and invasion $(15,16)$. PCBP2 was also upregulated in human gastric cancer and promoted gastric carcinoma development by regulating the level of miR-34a (17). Our previous study also identified that PCBP2 was significantly upregulated in pancreatic ductal adenocarcinoma (PDAC) and knockdown of PCBP2 attenuated cell proliferation and colony formation through triggering 
c-Myc expression (18). Moreover, PCBP2 has been reported to participate in the replication and translation of hepatitis $\mathrm{C}$ virus (HCV) (19-21), and silencing of PCBP2 expression reversed the alcohol-induced pro-fibrogenic effects in hepatic stellate cells (22). More importantly, Leidgens et al found that PCBP2 was expressed in Huh7 cells, one of the HCC cell lines (23). However, whether PCBP2 participates in human HCC development and clinical significance remains largely elusive.

In the present study, we showed that PCBP 2 expression was significantly increased in human HCC specimens and cell lines. In addition, we evaluated the correlation between PCBP2 expression and biological and clinical indices, as well as the prognostic value of PCBP2 for predicting the HCC patient survival rate. Furthermore, we discovered that depletion of PCBP2 critically attenuated the proliferation of $\mathrm{HCC}$ cells. In addition, we found that high expression of PCBP2 may contribute to sorafenib resistance in HCC cells. These results showed that PCBP2 may be a novel prognostic marker of HCC and targeting PCBP2 may have therapeutic implications for the treatment of HCC in clinical practice.

\section{Materials and methods}

Patients and tissue specimens. The fresh-frozen human HCC tissues and adjacent normal tissues were obtained from eight patients who underwent surgery without preoperative systemic chemotherapy between 2003 and 2011 at the Department of Surgery, the Affiliated Hospital of Nantong University. All tissues were from patients with newly diagnosed HCC who had received no therapy before sample collection, and were snap-frozen in liquid nitrogen immediately after surgery and stored at $-80^{\circ} \mathrm{C}$ until use. The liver cancer tissue microarrays containing 65 matched primary HCC and adjacent non-tumorous tissues were obtained from the Department of Pathology of the Affiliated Hospital of Nantong University. The study population consisted of 40 males and 25 females, and the age ranged from 21 to 69 years. The total cases of HCC patients had been approved by the Ethics Committee of the Affiliated Hospital of Nantong University. The main clinical and pathologic variables are summarized in Table I.

Immunohistochemistry. In order to analyze PCBP2 and Ki67, serial sections ( $5 \mu \mathrm{m}$ thick) were mounted on glass slides coated with $10 \%$ polylysine. These sections were dewaxed in xylene and rehydrated through graded alcohol. Immunoreactivity was enhanced by high temperature and pressure, and these sections were boiled in $0.01 \mathrm{M}$ citrate buffer ( $\mathrm{pH} \mathrm{6.0)}$ ) for $20 \mathrm{~min}$ in an autoclave to retrieve the antigen. Thereafter, endogenous peroxidase activity was blocked using hydrogen peroxide $(0.3 \%)$. Anti-PCBP2 antibody (1:200; Santa Cruz Biotechnology, Inc. Santa Cruz, CA, USA) overnight at $4^{\circ} \mathrm{C}$ and anti-Ki67 antibody (1:500; Millipore Corp., Bedford, MA, USA) for $4 \mathrm{~h}$ at room temperature were incubated in the sections after rinsing in phosphate-buffered saline (PBS) ( $\mathrm{pH}$ 7.2). Negative control slides were incubated in parallel using a nonspecific immunoglobulin IgG (Sigma-Aldrich, St. Louis, MO, USA) at the same concentration as the primary antibody. All slides were processed using the peroxidase-anti-peroxidase method (Dako, Hamburg, Germany). Finally, slides were counterstained with
Table I. Clinicopathological features of HCC in relation to the PCBP2 expression pattern.

\begin{tabular}{|c|c|c|c|c|}
\hline \multirow{2}{*}{$\begin{array}{l}\text { Clinicopathological } \\
\text { features }\end{array}$} & \multirow[b]{2}{*}{ Total } & \multicolumn{2}{|c|}{ PCBP2 } & \multirow[b]{2}{*}{ P-value } \\
\hline & & Low & High & \\
\hline \multicolumn{5}{|l|}{ Age (years) } \\
\hline$<45$ & 21 & 8 & 13 & \multirow[t]{2}{*}{0.829} \\
\hline$\geq 45$ & 44 & 18 & 26 & \\
\hline \multicolumn{5}{|l|}{ Gender } \\
\hline Female & 25 & 13 & 12 & \multirow[t]{2}{*}{0.118} \\
\hline Male & 40 & 13 & 27 & \\
\hline \multicolumn{5}{|l|}{$\begin{array}{l}\text { Serum AFP } \\
\text { level (ng/ml) }\end{array}$} \\
\hline$<50$ & 14 & 4 & 10 & \multirow[t]{2}{*}{0.324} \\
\hline$\geq 50$ & 51 & 22 & 29 & \\
\hline \multicolumn{5}{|l|}{ Cirrhosis } \\
\hline Absent & 19 & 7 & 12 & \multirow[t]{2}{*}{0.738} \\
\hline Present & 46 & 19 & 27 & \\
\hline \multicolumn{5}{|l|}{ HBsAg } \\
\hline Negative & 27 & 15 & 12 & \multirow[t]{2}{*}{$0.031^{\mathrm{a}}$} \\
\hline Positive & 38 & 11 & 27 & \\
\hline \multicolumn{5}{|l|}{ Tumor no. } \\
\hline Single & 43 & 18 & 25 & \multirow[t]{2}{*}{0.669} \\
\hline Multiple & 22 & 8 & 14 & \\
\hline \multicolumn{5}{|l|}{$\begin{array}{l}\text { Maximal tumor } \\
\text { size }(\mathrm{cm})\end{array}$} \\
\hline$<4.5$ & 31 & 12 & 19 & \multirow[t]{2}{*}{0.839} \\
\hline$\geq 4.5$ & 34 & 14 & 20 & \\
\hline \multicolumn{5}{|l|}{ Tumor metastasis } \\
\hline Absent & 46 & 17 & 29 & \multirow[t]{2}{*}{0.436} \\
\hline Present & 19 & 9 & 10 & \\
\hline \multicolumn{5}{|l|}{$\begin{array}{l}\text { Microvascular } \\
\text { invasion }\end{array}$} \\
\hline Absent & 38 & 12 & 26 & \multirow[t]{2}{*}{0.100} \\
\hline Present & 27 & 14 & 13 & \\
\hline \multicolumn{5}{|l|}{ Tumor differentiation } \\
\hline Well & 27 & 16 & 11 & \multirow[t]{3}{*}{$0.028^{\mathrm{a}}$} \\
\hline Moderate & 19 & 5 & 14 & \\
\hline Poor & 19 & 5 & 14 & \\
\hline \multicolumn{5}{|l|}{ Capsular formation } \\
\hline Present & 36 & 11 & 25 & \multirow[t]{2}{*}{0.083} \\
\hline Absent & 29 & 15 & 14 & \\
\hline \multicolumn{5}{|l|}{ Ki67 expression } \\
\hline Negative & 30 & 16 & 14 & $0.042^{\mathrm{a}}$ \\
\hline Positive & 35 & 10 & 25 & \\
\hline
\end{tabular}

Statistical analyses were carried out using Pearson's $\chi^{2}$ test. ${ }^{\mathrm{a}} \mathrm{p}<0.05$ was considered significant. HCC, hepatocellular carcinoma; $\mathrm{PCBP} 2$, poly $(\mathrm{C})$ binding protein 2 .

hematoxylin, dehydrated, and mounted in resin mount. Stained sections were observed under a microscope (24). 
Immunohistochemistry evaluation. The immunostaining results were evaluated by two independent pathologists to avoid possible technical errors. Five high-power fields were randomly chosen for assessment of PCBP2, and at least 500 cells were counted per field. Each tumor section was assigned a score according to the intensity of the cytoplasmic staining and the proportion of stained tumor cells. The intensity of staining was scored as 0 (negative), 1 (weak), 2 (moderate), or 3 (strong). The extent of staining was scored based on the percentage of positive tumor cells: $0(<10 \%)$, $1(10-30 \%), 2$ (>30-50\%), 3 (>50-70\%), and 4 (>70\%). The immunostaining score was counted as the percentage positive score $\mathrm{x}$ the staining intensity score and ranged from 0 to 12 . A score of 0 was considered negative; $1-4$, weak; 5-9, moderate; and 10-12, strong. For statistical analysis, 0-4 was counted as low expression, while 5-12 was counted as high expression.

Cell culture and transfection. The human HCC cell lines, HepG2, Huh7, SMMC-7721 and Hep3B and the normal liver cell line (LO2) were obtained from Shanghai Institute of Cell Biology, Academia Sinica, and maintained in Dulbecco's modified Eagle's medium (DMEM) supplemented with $10 \%$ fetal bovine serum (FBS), streptomycin $100 \mu \mathrm{g} / \mathrm{ml}$, and penicillin $100 \mathrm{U} / \mathrm{ml}$ at $37^{\circ} \mathrm{C}$ in $5 \% \mathrm{CO}_{2}$. The siRNA oligos of PCBP2 were synthesized by GeneChem Co., Ltd. (Shanghai, China). The targeted sequences of $P C B P 2$ siRNA were as follows: siRNA\#1, CATCACTATTGCTGGCATT; siRNA\#2, CACTAATGCCATCTTCAAA; siRNA\#3, CGGATTCAGT GGCATTG; and control, TTCTCCGAATGTCACGT. Cell transfection was performed using Lipofectamine 2000 (Invitrogen, Carlsbad, CA, USA) according to the manufacturer's instructions.

Western blot analysis. Western blot analysis was conducted as previously described (25). Briefly, frozen liver tissues and harvested cells were promptly homogenized in a homogenization buffer $(50 \mathrm{mM}$ Tris-Cl, $\mathrm{pH} 7.5,150 \mathrm{mM}$ $\mathrm{NaCl}, 1 \%$ NP-40, 5 mM EDTA, 5 mM EGTA, $15 \mathrm{mM} \mathrm{MgCl}_{2}$, $60 \mathrm{mM}$ b-glycerophosphate, $0.1 \mathrm{mM}$ sodium orthovanadate, $0.1 \mathrm{mM} \mathrm{NaF}$ ) and then centrifuged at $10,000 \mathrm{x} \mathrm{g}$ for $30 \mathrm{~min}$ to collect the supernatant. Protein concentrations were determined using a Bio-Rad BCA protein assay (Bio-Rad Laboratories, Inc., Hercules, CA, USA). Equal amounts of protein samples were separated by $10 \%$ SDS-polyacrylamide gel electrophoresis (SDS-PAGE) and transferred to polyvinylidene fluoride (PVDF) filter membranes (Millipore Corp.). The membranes were blocked with 5\% dried skim milk in TBST (20 mM Tris-Cl, $150 \mathrm{mM} \mathrm{NaCl}, 0.05 \%$ Tween-20) and incubated with primary antibodies overnight at $4^{\circ} \mathrm{C}$. The primary antibodies used in the study were as follows: anti-PCBP2 (1:1,000), anti-PCNA $(1: 1,000)$, cyclin D1 (1:500), anti-p27 (1:1,000), anti-Bax (1:500); anti-Bcl-2 (1:500), anti-active caspase-3 (1:500) (all from Santa Cruz Biotechnology, Inc.), and anti-GAPDH (1:1,000; Sigma-Aldrich). The membranes were washed with TBST for $5 \mathrm{~min}$ for three times. Then, horseradish peroxidase-linked IgG was used as the secondary antibody (1:5,000; Pierce Biotechnology, Inc., Rockford, IL, USA) for $2 \mathrm{~h}$ at room temperature according to the manufacturer's instructions. The detection of immunoreactive bands was performed using an enhanced chemiluminescence system (NEN Life Science Products, Inc., Boston, MA, USA).

Cell Counting Kit-8. Cell proliferation was measured using Cell Counting Kit-8 (CCK-8) assay (Dojindo Laboratories, Kumamoto, Japan) following the manufacturer's instructions. Briefly, cells were plated into a 96-well plate at a density of $1 \times 10^{4}$ cells/well in a volume of $100 \mu \mathrm{l}$. For proliferation measurement, $10 \mu \mathrm{l}$ of CCK-8 reagent plus $90 \mu \mathrm{l}$ of DMEM complete medium was added to each well for a 2-h incubation at $37^{\circ} \mathrm{C}$. The absorbance of cells was read in a microplate reader (Bio-Rad Laboratories, Inc.) at $450 \mathrm{~nm}$ with a reference wavelength of $650 \mathrm{~nm}$. The detection of cell absorbance was performed every $24 \mathrm{~h}$. The experiments were repeated at least three times (26).

Plate colony formation assay. After transfection, HepG2 and Huh7 cells were plated into a 6 -well plate (500 cells/well). Fifteen days later, the colonies were washed with PBS, fixed with paraformaldehyde for $20 \mathrm{~min}$, and then stained with $0.5 \%$ crystal violet for $30 \mathrm{~min}$. Cell colonies $(0.5 \mathrm{~mm}$ in diameter $)$ were counted after staining.

Annexin-V/PI apoptotic analysis. The apoptosis of HCC cells was evaluated by FITC-Annexin V and propidium iodide (PI) assay using a commercial kit (BD Biosciences, Shanghai, China) as previously described (27). The upper right quadrant (UR) indicates the late apoptotic and necrotic cells, the lower right quadrant (LR) represents the early apoptotic cells, the upper left quadrant (UL) represents the debris and damaged cells, while the lower left quadrant (LL) represents the negative control cells. In this study, we consider UR and LR as apoptotic cells.

Statistical analysis. The results are expressed as mean \pm SEM. Statistical analysis was performed using the Stata 7.0 software package. The association between PCBP2 expression and clinicopathological features was analyzed using the $\chi^{2}$ test. For analysis of survival data, Kaplan-Meier curves were constructed, and the log-rank test was performed. For multivariate analysis, Cox's proportional hazards model was used and $\mathrm{p}<0.05$ was considered to be statistically significant.

\section{Results}

PCBP2 is highly expressed in HCC tissues and cell lines. To determine the expression of PCBP2 in HCC tissues, we first studied the expression of PCBP2 in HCC tissues and the adjacent non-tumor liver tissues by western blot analysis. As shown in Fig. 1A, we found that the expression of PCBP2 was significantly elevated in the HCC tissues, compared with that in the adjacent normal ones. Moreover, the expression profile of PCBP2 was detected in the HCC cell lines (HepG2, Huh7 and SMMC-7721) and the normal liver cell line (LO2). Similarly, we found that HCC cell lines had a higher PCBP2 level compared with that noted in the normal liver LO2 cells (Fig. 1B). Then, we conducted immunohistochemical staining to confirm the expression of PCBP2 and Ki67 in the HCC specimens. Following the different histological stage, representative samples of PCBP2 and Ki67 are shown 
A

$\begin{array}{llllllll}\text { T1 } & \mathrm{N} 1 & \mathrm{~T} 2 & \mathrm{~N} 2 & \mathrm{~T} 3 & \mathrm{~N} 3 & \mathrm{~T} 4 & \mathrm{~N} 4\end{array}$
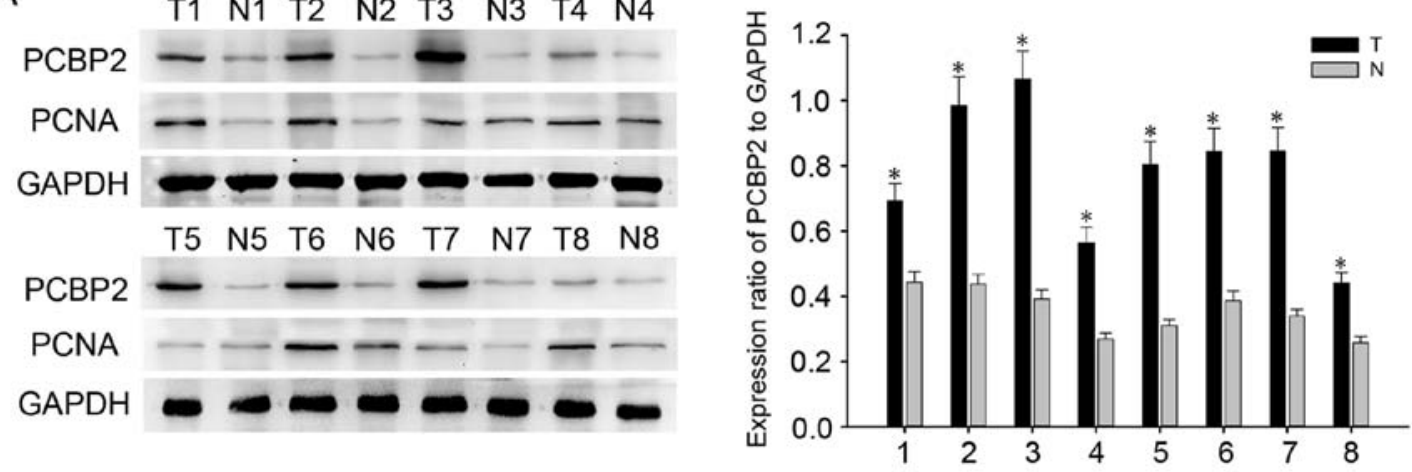

B
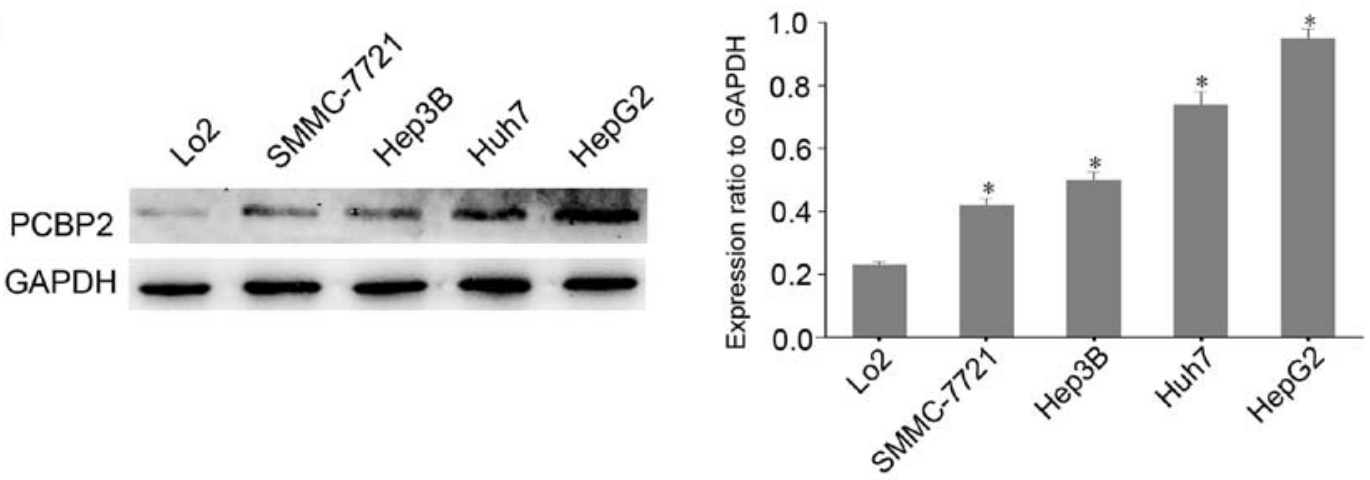

C

PCBP2

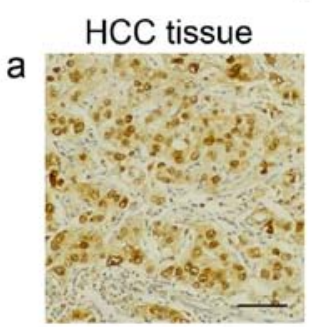

Adjacent normal tissue

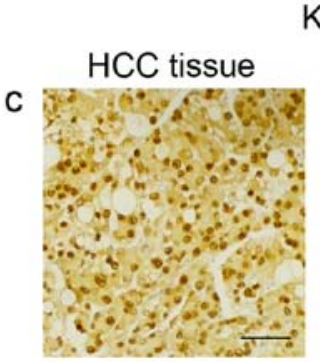

Ki67

b

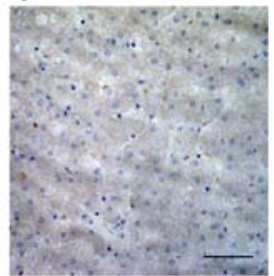

Adjace

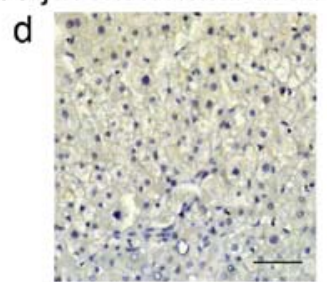

Figure 1. Poly(C)-binding protein 2 (PCBP2) is upregulated in hepatocellular carcinoma (HCC) tissues and cell lines. (A) The levels of PCBP2 and PCNA in eight representative paired HCC (T) and adjacent normal tissues (N) were examined by western blot analysis. GAPDH was used as a control for protein load and integrity. The bar chart represents the ratio of PCBP2 to GAPDH by densitometry. The data are mean \pm SEM of three independent experiments $\left({ }^{*} \mathrm{p}<0.05\right.$, tumor tissues compared with adjacent non-tumor tissues). (B) Western blot analysis showing the PCBP2 expression in different HCC cells and normal liver cells (LO2). The bar chart represents the ratio of PCBP2 to GAPDH by densitometry. The data are reported as the mean \pm SEM of three independent experiments ("p<0.05, compared with the level in LO2 cells). (C) Immunohistochemical evaluation of PCBP2 and Ki67 levels. PCBP2 and Ki67 were highly expressed in HCC tissues (a and c) compared with the paired normal tissues (b and d). Scale bar, $100 \mu \mathrm{m}$.

in Fig. 1C. In most specimens, PCBP2 was highly expressed in the cytoplasm and nucleus of the HCC tissues, whereas an obvious low signal of PCBP2 was observed in the adjacent non-tumor tissue samples (Fig. 1C-a and -b), which is in line with the expression of Ki-67 (Fig. 1C-c and -d). These findings indicated that $\mathrm{PCBP} 2$ may contribute to malignant progression of HCC.

Relationship between $P C B P 2$ expression and clinicopathological parameters of $H C C$. To further investigate the significance and prognostic value of PCBP2, we analyzed the correlations between clinicopathological characteristics and the expression of PCBP2 in 65 patients with HCC. The results are summarized in Table I. We found that the expression of PCBP2 was correlated with tumor differentiation $(\mathrm{p}=0.028), \operatorname{HBsAg}(\mathrm{p}=0.031)$ and Ki67 expression $(\mathrm{p}=0.042)$, but not with other clinicopathological factors, such as age, gender, tumor size, tumor number, tumor metastasis, serum
AFP level, cirrhosis, microvascular invasion and capsular formation.

The prognostic significance of PCBP2 expression. Next, we performed Kaplan-Meier analysis to examine whether PCBP2 could serve as an independent indicator to predict the prognosis of HCC patients. Our data showed that patients with high PCBP2 expression had significantly worse prognosis compared with that of patients with low PCBP2 expression (Fig. 2). Based on the results of univariate analyses, we identified that PCBP2 expression $(\mathrm{p}=0.016), \mathrm{Ki} 67(\mathrm{p}=0.018)$, tumor differentiation $(\mathrm{p}=0.007)$ and HBsAg $(\mathrm{p}=0.036)$ were associated with patient survival. Furthermore, multivariate Cox proportional hazard analysis showed that PCBP2 $(\mathrm{p}=0.043)$ could be an independent prognostic indicator of overall survival (Table II).

PCBP2 is highly expressed in proliferating HCC cells. Based on our data that PCBP2 expression is associated with PCNA 


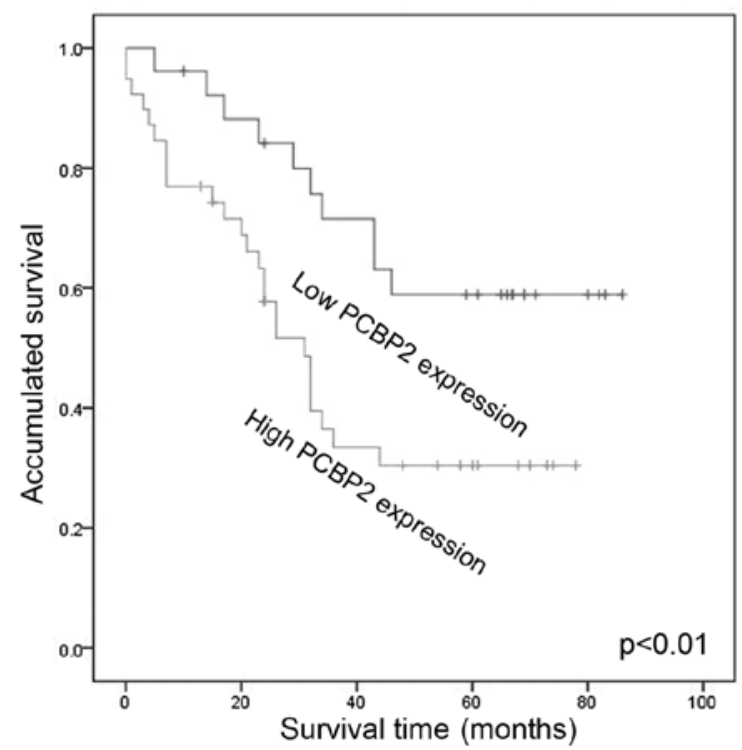

Figure 2. Kaplan-Meier survival curves according to poly(C)-binding protein 2 (PCBP2) expression in 65 patients with hepatocellular carcinoma (HCC). Patients with high expression of PCBP2 had significantly shorter overall survival $(\mathrm{p}<0.01)$.

and Ki67, we considered that PCBP2 may promote HCC development by regulating the proliferation of HCC cells. Therefore, we analyzed the expression of PCBP2 during cell cycle progression in HCC cells. HepG2 and Huh7 cells were arrested in G1 phase by serum deprivation for $72 \mathrm{~h}$. After serum-refeeding, the cells were released from G1 phase and entered into the $\mathrm{S}$ phase (Fig. 3A and B). Western blot analysis showed that the expression of PCBP2 increased gradually with time following the release of cells from serum starvation in both cell lines. At the same time, we found that the expression of cyclin D1 was upregulated (Fig. 3C-F). These results suggest that PCBP2 may play a key role in regulating HCC cell proliferation.

Depletion of PCBP2 inhibits cell proliferation in HCC. To determinate the effect of PCBP2 in HCC cell proliferation, we firstly transfected HepG2 and Huh7 cells with PCBP2 siRNA oligos to knockdown endogenous PCBP2. Western blot analysis was carried out at $48 \mathrm{~h}$ after transfection, which confirmed a significant reduction in PCBP2 expression in the PCBP2-siRNA\#3-transfected cells (Fig. 4A). Therefore, PCBP2-siRNA\#3 was used for further experiments. At the same time, we discovered that the silencing of PCBP2 expression obviously downregulated the levels of cyclin D1 and PCNA, with the upregulated levels of cyclin-dependent kinase inhibitor p27 (Fig. 4B). Furthermore, CCK-8 assay was used to confirm the effect of PCBP2 on HCC cell proliferation. The HepG2 and Huh7 cells transfected with PCBP2 siRNA\#3 exhibited a marked decreased in the cell proliferation, as compared with the control siRNA-transfected ones (Fig. 4C). Likewise, colony formation assay revealed that depletion of PCBP2 markedly inhibited the colony formation capacity of the HepG2 and Huh7 cells (Fig. 4D). According to the above results, we further demonstrated whether PCBP2 expression could affect the cell cycle distribution in HCC cells by flow cytometric analysis. The results showed that depletion of PCBP 2 caused G0/G1 phase arrest, accompanying a marked reduction in the cell population in the S phase (Fig. 4E). These results suggest that depletion of PCBP2 inhibits the proliferation of HCC cells.

High expression of PCBP2 in HCC cells contributes to sorafenib resistance. Sorafenib (Nexavar), a multiple kinase inhibitor, has shown survival benefits in patients with advanced $\mathrm{HCC}$ and has become the first approved drug for HCC $(28,29)$. However, the clinical response of sorafenib

Table II. Contribution of various potential prognostic factors to survival by Cox regression analysis in HCC speciments.

\begin{tabular}{|c|c|c|c|c|c|c|}
\hline \multirow[b]{2}{*}{ Parameters } & \multirow[b]{2}{*}{ HR } & \multicolumn{2}{|c|}{ Univariate analysis } & \multirow[b]{2}{*}{ HR } & \multicolumn{2}{|c|}{ Multivariate analysis } \\
\hline & & $95 \% \mathrm{CI}$ & P-value & & $95 \% \mathrm{CI}$ & P-value \\
\hline Age (years) & 1.030 & $0.494-2.148$ & 0.937 & & & \\
\hline Gender & 0.587 & $0.302-1.144$ & 0.118 & & & \\
\hline Serum AFP level (ng/ml) & 0.562 & $0.269-1.171$ & 0.124 & & & \\
\hline Cirrhosis & 1.406 & $0.658-3.002$ & 0.379 & & & \\
\hline Tumor no. & 0.979 & $0.479-2.000$ & 0.954 & & & \\
\hline Maximal tumor size $(\mathrm{cm})$ & 0.913 & $0.470-1.773$ & 0.787 & & & \\
\hline Tumor metastasis & 1.077 & $0.517-2.245$ & 0.843 & & & \\
\hline Microvascular invasion & 1.161 & $0.594-2.269$ & 0.662 & & & \\
\hline HBsAg & 2.197 & $1.051-4.592$ & $0.036^{\mathrm{a}}$ & 1.141 & $0.287-4.529$ & 0.851 \\
\hline Tumor differentiation & 1.784 & $1.174-2.712$ & $0.007^{\mathrm{a}}$ & 1.532 & $0.877-2.675$ & 0.134 \\
\hline Capsular formation & 0.685 & $0.353-1.330$ & 0.264 & & & \\
\hline Ki67 & 2.370 & $1.158-4.858$ & $0.018^{\mathrm{a}}$ & 1.231 & $0.277-5.461$ & 0.880 \\
\hline PCBP2 & 2.471 & $1.181-5.172$ & $0.016^{\mathrm{a}}$ & 2.169 & $1.024-4.592$ & $0.043^{\mathrm{a}}$ \\
\hline
\end{tabular}

Statistical analyses were performed by the Cox test analysis. ${ }^{\mathrm{a}} \mathrm{p}<0.05$ was considered significant. $\mathrm{HCC}$, hepatocellular carcinoma; $\mathrm{PCBP} 2$, poly $(\mathrm{C})$ binding protein 2 . 
A

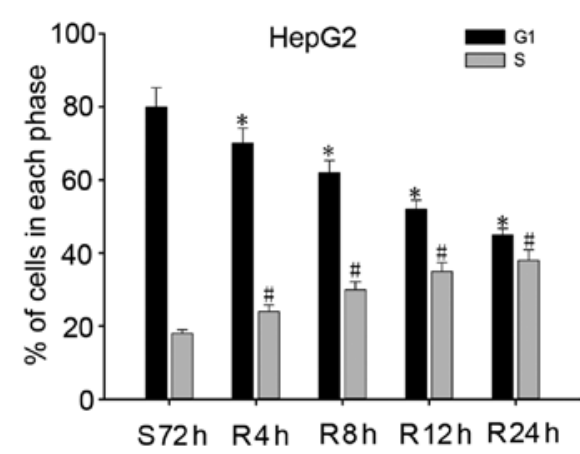

C

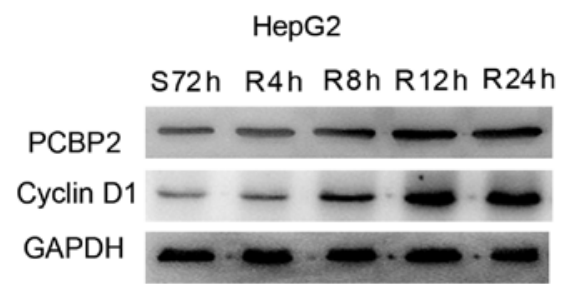

E

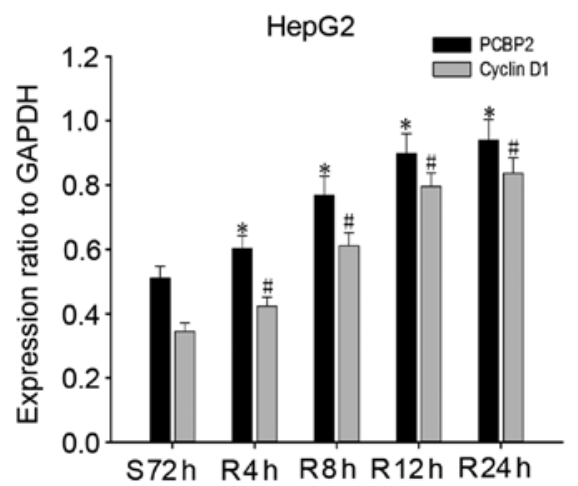

B

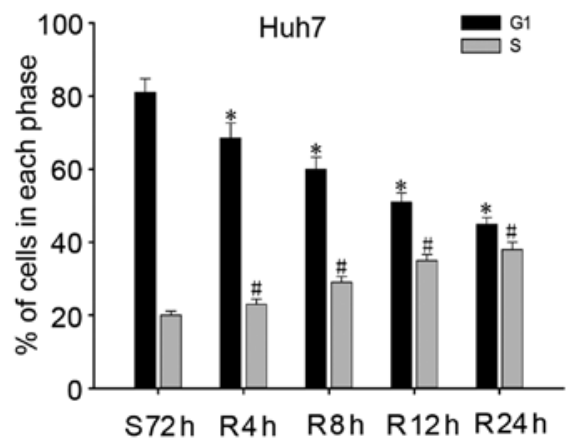

D

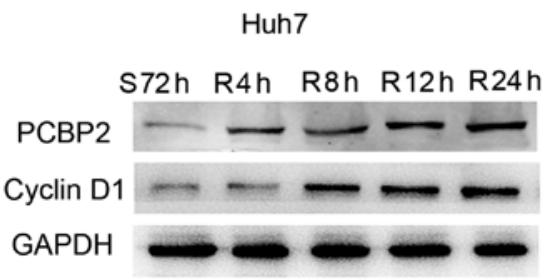

$\mathrm{F}$

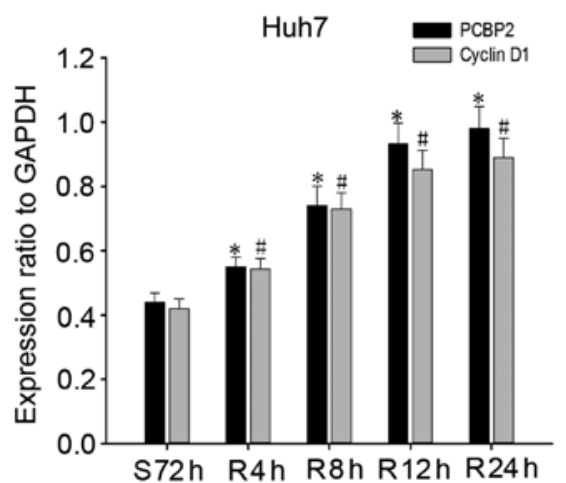

Figure 3. Poly(C)-binding protein 2 (PCBP2) is upregulated in proliferating hepatocellular carcinoma (HCC) cells. (A and B) Flow cytometric analysis of cell cycle distribution in HepG2 and Huh7 cells. Cells were synchronized at G1 after serum starvation for $72 \mathrm{~h}$, and progressed into S phase after serum refeeding for the indicated time-periods ( R4, R8, R12 and R24 h). These data are the mean \pm SEM of three independent experiments $\left(^{*}, \# p<0.05\right)$. (C and D) The levels of PCBP2 and cyclin D1 were examined by western blot analysis after serum starvation and refeeding in HepG2 and Huh7 cells. (E and F) The bar chart shows the ratio of PCBP2 and cyclin D1 expression relative to GAPDH by densitometry in HepG2 and Huh7 cells. The data are the mean \pm SEM of three independent experiments $\left.{ }^{*}, \# \mathrm{p}<0.05\right)$. $\mathrm{S}$, serum starvation; $\mathrm{R}$, serum refeeding.

was seriously limited by drug resistance and thus we tested the possibility that high expression of PCBP2 may be involved in sorafenib resistance in HCC. We firstly investigated the sensitivity of HCC cells to sorafenib. The results showed that sorafenib induced the apoptosis of HCC cells in a dose-dependent manner (Fig. 5A). Then we transfected HepG2 cells with PCBP2 siRNAs\#3 or control siRNA, and exposed the cells to sorafenib $(50 \mu \mathrm{M})$ or DMSO. The flow cytometric analysis showed that depletion of PCBP2 significantly increased the percentage of apoptotic cells in the absence of sorafenib treatment (33.56 vs. 55.64\%). Following sorafenib treatment, PCBP2-depleted cells exhibited a markedly increased level of apoptosis (59.01 vs. 78.38\%), compared with the mock-transfected group (Fig. 5B). The bar chart shows the ratio of apoptotic cells by densitometry (Fig. 5C). These results revealed that interference of PCBP2 could potentiate HCC cells to sorafenib-induced apoptosis. Furthermore, western blot analysis showed that transfection with PCBP2 siRNA\#3 significantly increased the level of active caspase-3, Bax and inhibited the level of
Bcl-2, especially after sorafenib treatment (Fig. 5D). The bar chart shows the ratio of PCBP2, active caspase-3, Bax and Bcl-2 expression to GAPDH (Fig. 5E). These results indicate that high expression of PCBP2 may contribute to sorafenib resistance by regulating $\mathrm{Bcl}-2$ proteins in $\mathrm{HCC}$ cells.

\section{Discussion}

HCC represents one of the most common cancer types worldwide, with a low survival rate (30). Despite that significant improvements have been made to better understanding the molecular mechanism underlying HCC initiation and progression, the diagnosis of $\mathrm{HCC}$ remains delayed and the prognosis of HCC patients remains poor $(2,31)$. Thus, the development of novel molecular targets and more effective anti-neoplastic therapies are urgent for us to improve the survival rate of this deadly disease.

PCBP2, as a member of the PCBP family, has been reported to be overexpressed in pancreatic cancer, glioma, gastric carcinoma and prostate cancer. Consistently, we found 
A

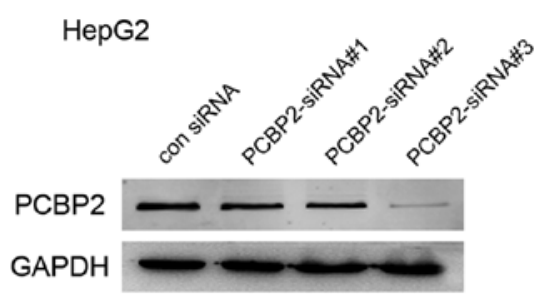

B

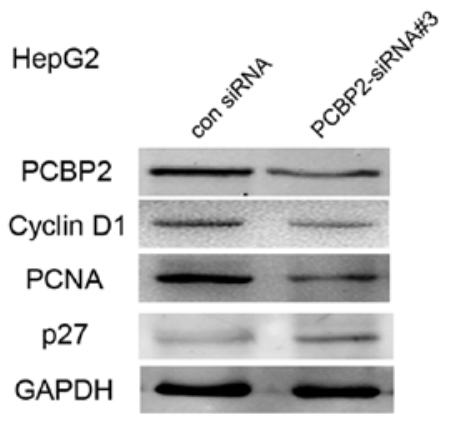

C

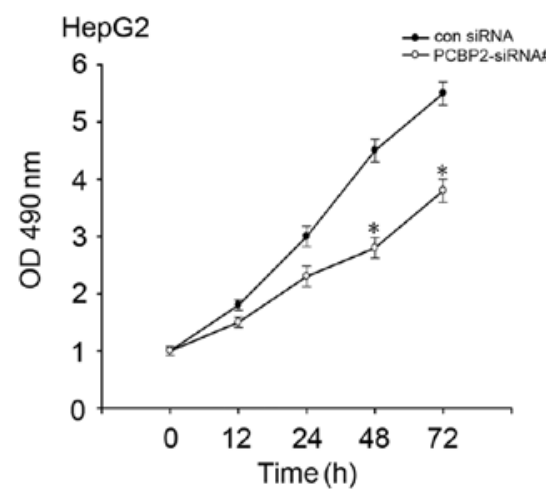

D

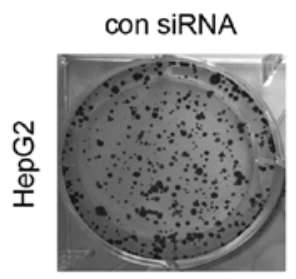

PCBP2-SiRNA\#3

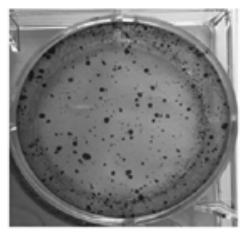

E
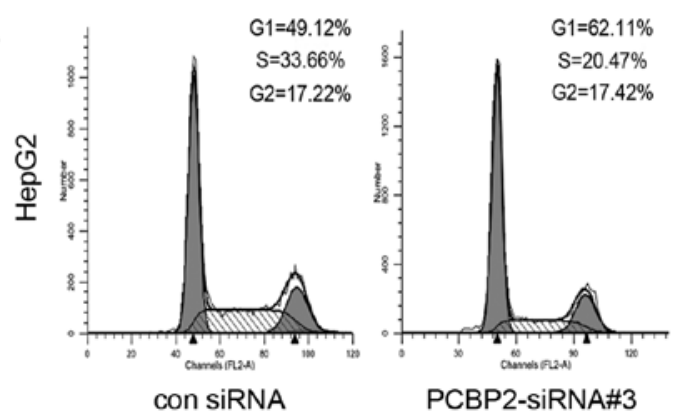
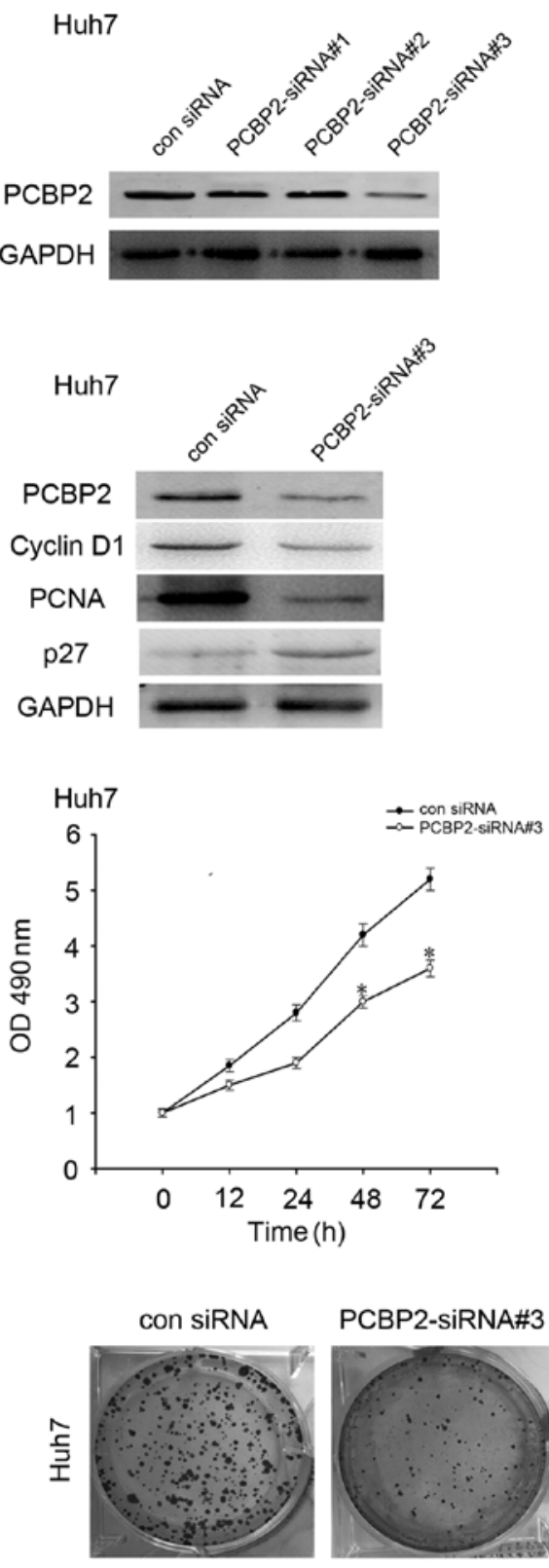

PCBP2-SiRNA\#3
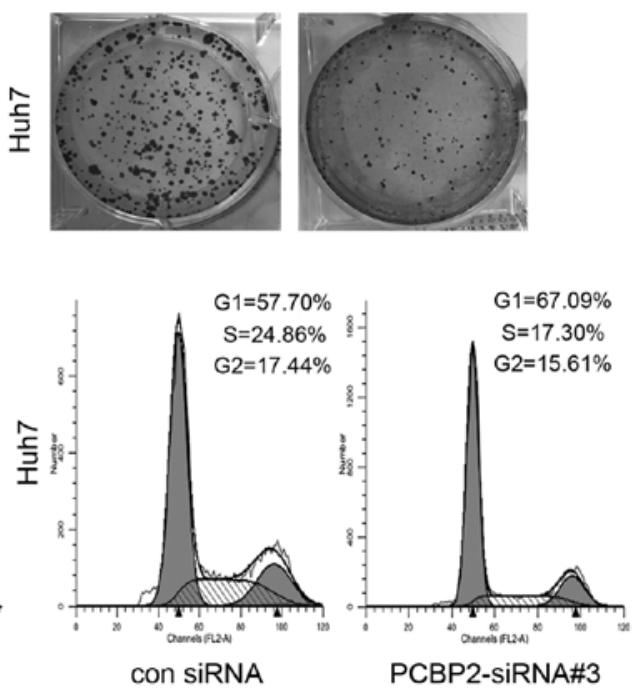

Figure 4. Silencing of poly(C)-binding protein 2 (PCBP2) expression decreases hepatocellular carcinoma (HCC) cell proliferation and cell cycle progression. (A) Determination of the knockdown efficiencies of three PCBP2-targeting siRNA oligos in HepG2 and Huh7 cells. PCBP2-siRNA\#3 exhibited the best knockout efficiency. (B) Representative western blot analysis showing cyclin D1, PCNA and p27 protein levels in PCBP2-depleted HepG2 and Huh7 cells. (C) Cell Counting Kit-8 (CCK-8) assay measured the viability of HepG2 and Huh7 cells transfected with PCBP2-siRNA\#3 and control siRNA. The data are the mean \pm SEM of three independent experiments ( ${ }^{*}$ p<0.05). (D) PCBP2 knockdown suppressed plate colony formation. Equal numbers of HepG2 and Huh7 cells after transfection were seeded onto 60-mm plates. The cells were fixed and stained with crystal violet after 14 days. (E) Approximately $48 \mathrm{~h}$ after transfection, HepG2 and Huh7 cells were stained with PI for DNA content analysis by FACS. All data are representative of three independent experiments.

that PCBP2 was also highly expressed in HCC. Moreover, our study showed that PCBP2 expression was associated with HBsAg expression. Since HCC is closely related with $\mathrm{HBV}$ infection in many countries, we speculated that this 
A

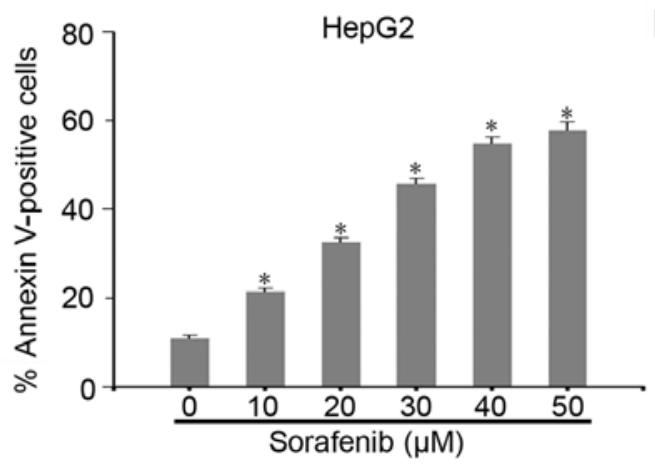

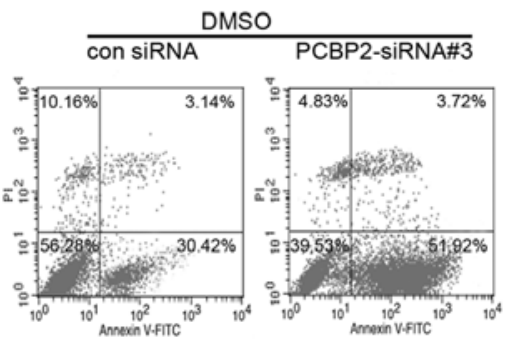
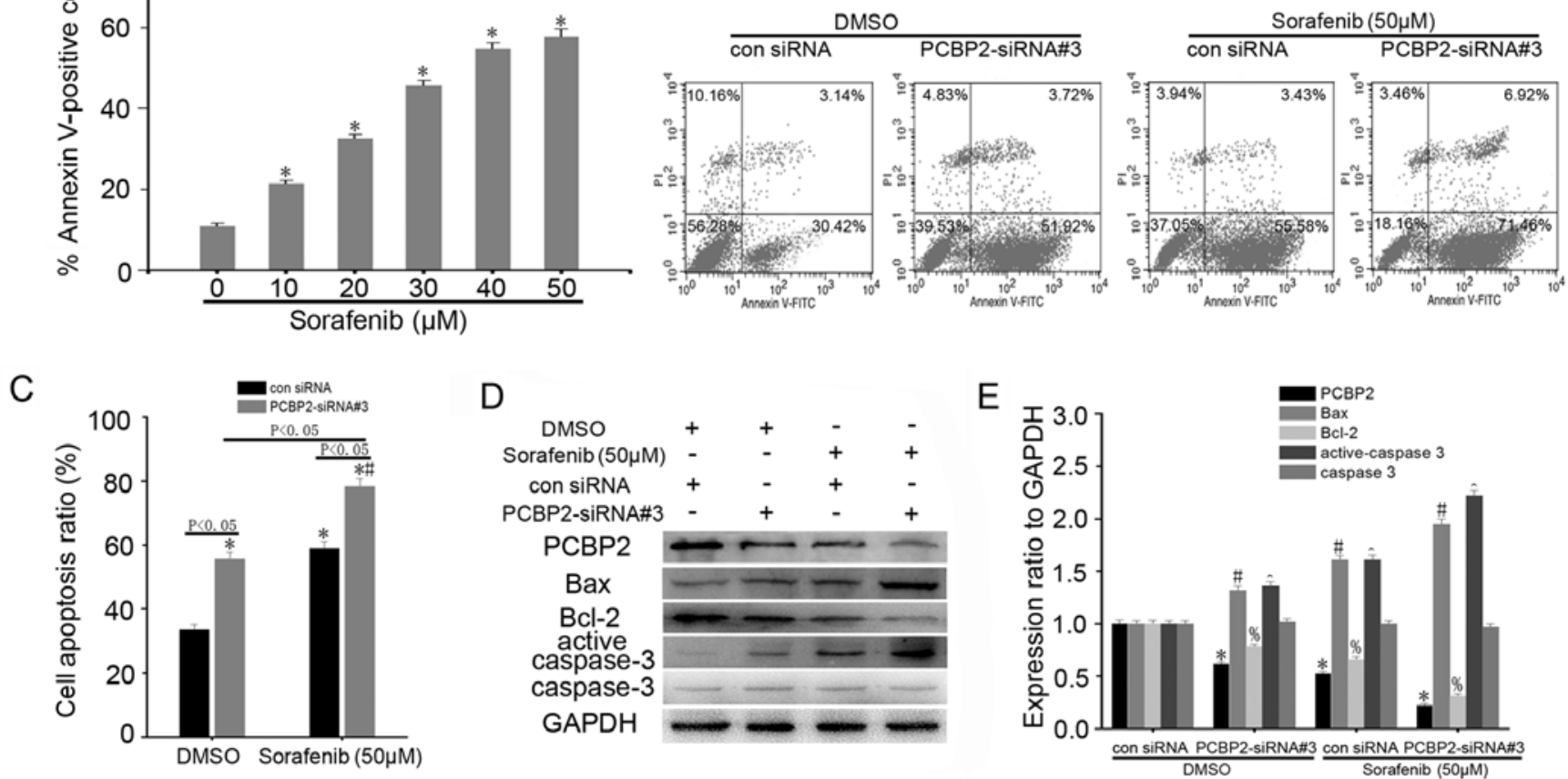

Figure 5. High expression of poly(C)-binding protein 2 (PCBP2) contributes to sorafenib resistance in hepatocellular carcinoma (HCC) cells. (A) Annexin V/PI staining analysis of the apoptosis in HepG2 cells following different doses $(0,10,20,30,40$ and $50 \mu \mathrm{M})$ of sorafenib exposure for $24 \mathrm{~h}$. Data are represented as the mean \pm SEM from three independent experiments ( $\mathrm{P}<0.05)$. (B) FITC-Annexin V/PI apoptotic analysis of PCBP2-deleted HepG2 cells with or without sorafenib (50 $\mu \mathrm{M})$. Upper left quadrants (UL), debris and damaged cells; upper right quadrants (UR), late apoptotic and necrotic cells; lower left quadrants (LL), negative control cells; lower right quadrants (LR), early apoptotic cells. We consider UR and LR as apoptotic cells. (C) The bar chart indicates the ratio of apoptotic cells by densitometry. Data are represented as the mean \pm SEM from three independent experiments $\left({ }^{*} \mathrm{p}<0.05\right.$, $\left.{ }^{* *} \mathrm{p}<0.05\right)$. (D) HepG2 cells were transfected with control siRNA or PCBP2 siRNA\#3, and then incubated with $50 \mu \mathrm{M}$ sorafenib or vehicle (DMSO) for 24 h. The cell lysates were subjected to western blot analysis using the indicated antibodies. (E) The bar chart shows the ratio of PCBP2, active caspase-3, Bax and Bcl-2 expression to GAPDH. Data are represented as the mean \pm SEM from three independent experiments $\left({ }^{*} \#, \%, \wedge<0.05\right)$.

result may indicate a potential involvement of $\mathrm{PCBP} 2$ in $\mathrm{HBV}$-associated HCC development. At the same time, the Cox regression analysis suggested that $\mathrm{PCBP} 2$ represented a novel independent indicator of HCC prognosis. In particular, we found that PCBP2 is associated with HCC cell growth and sorafenib resistance. Taken together, the above data suggest that PCBP2 may be a novel prognostic indicator and therapeutic target of HCC.

The molecular mechanism underlying the oncogenic property of PCBP2 remains largely elusive. There have been several studies indicating that PCBP2 functions via regulation of miRNA pathways, such as miR-328, miR-34a and miR-16, to promote the growth of tumors $(16,17,32)$. Koganti et al found that STAT3 exploited cellular PCBP2 to regulate the refractory state in EBV-positive Burkitt lymphoma (33). It has been found that PCBP2 depletion inhibits tumor cell growth through inhibition of cell-cycle progression and induction of apoptosis $(15,17)$. In our study, we discovered that PCBP2 promoted HCC cell growth involving dysregulated expression of cyclin-dependent kinase inhibitor $\mathrm{p} 27$, which plays a pivotal roles in cell cycle regulation. Then, we speculated that PCBP2 aberrantly regulated cell cycle progression and eventually transformed into HCC, which was confirmed by flow cytometry analysis (Fig. 4E). More importantly, we first found that depletion of PCBP2 enhanced sorafenib cytotoxicity in HCC cells, which was accompanied by altered expression of Bax and Bcl-2. Rencently, the genomic amplification of oncogenes has been reported to play a key role in hepatocarcinogenesis and drug resistance $(34,35)$. According to our study, we believe that the genomic amplification of PCBP2 may occur in human HCC, which may be associated with HCC development and sorafenib resistance. However, the specific mechanism remains obscure and needs further study.

In conclusion, our study first revealed that PCBP2 is overexpressed in HCC and is correlated with poor prognosis and shorter survival rate in HCC patients. Moreover, the expression of PCBP2 promotes cell cycle progression in HCC cells. In addition, we found that high expression of PCBP2 may contribute to aberrant proliferation and drug resistance in $\mathrm{HCC}$. We expect that these findings will accelerate our understanding of HCC development and PCBP2 may serve a candidate drug target for improving the survival of $\mathrm{HCC}$.

\section{Acknowledgements}

This study was supported by the National Natural Science Foundation of China (nos. 81502072, 81402024 and 81272708), the Nantong University on Key Basic Research Project (14Z023) and the Nantong Science and Technology Project (MS12015054) and a project funded by the Priority Academic Program Development of Jiangsu Higher Education Institutions (PAPD). 


\section{References}

1. Tsochatzis EA, Meyer T and Burroughs AK: Hepatocellular carcinoma. N Engl J Med 366: 92-93, author reply 92-93, 2012.

2. Malek NP, Schmidt S, Huber P, Manns MP and Greten TF: The diagnosis and treatment of hepatocellular carcinoma. Dtsch Arztebl Int 111: 101-106, 2014.

3. Llovet JM, Burroughs A and Bruix J: Hepatocellular carcinoma. Lancet 362: 1907-1917, 2003.

4. Finn RS: Development of molecularly targeted therapies in hepatocellular carcinoma: Where do we go now? Clin Cancer Res 16 390-397, 2010

5. Andino R, Böddeker N, Silvera D and Gamarnik AV: Intracellular determinants of picornavirus replication. Trends Microbiol 7: 76-82, 1999.

6. Blyn LB, Towner JS, Semler BL and Ehrenfeld E: Requirement of poly $(\mathrm{rC})$ binding protein 2 for translation of poliovirus RNA. J Virol 71: 6243-6246, 1997.

7. Collier B, Goobar-Larsson L, Sokolowski M and Schwartz S: Translational inhibition in vitro of human papillomavirus type 16 L2 mRNA mediated through interaction with heterogenous ribonucleoprotein $\mathrm{K}$ and poly(rC)-binding proteins 1 and 2 . J Biol Chem 273: 22648-22656, 1998 .

8. Tang FM, Li WM, Chen Y, Wang DM and Han J: Expression of hnRNP K in lung adenocarcinoma cells. Sichuan Da Xue Xue Bao Yi Xue Ban 39: 823-826, 2008 (In Chinese).

9. He Y, Brown MA, Rothnagel JA, Saunders NA and Smith R: Roles of heterogeneous nuclear ribonucleoproteins A and B in cell proliferation. J Cell Sci 118: 3173-3183, 2005.

10. Zhou ZJ, Dai Z, Zhou SL, Fu XT, Zhao YM, Shi YH, Zhou J and Fan J: Overexpression of HnRNP A1 promotes tumor invasion through regulating CD44v6 and indicates poor prognosis for hepatocellular carcinoma. Int J Cancer 132: 1080-1089, 2013

11. Liu Y, Gai L, Liu J, Cui Y, Zhang Y and Feng J: Expression of poly $(\mathrm{C})$-binding protein 1 (PCBP1) in NSCLC as a negative regulator of EMT and its clinical value. Int J Clin Exp Pathol 8: 7165-7172, 2015

12. Sean P, Nguyen JH and Semler BL: The linker domain of poly $(\mathrm{rC})$ binding protein 2 is a major determinant in poliovirus cap-independent translation. Virology 378: 243-253, 2008.

13. Sean P, Nguyen JH and Semler BL: Altered interactions between stem-loop IV within the 5' noncoding region of coxsackievirus RNA and poly(rC) binding protein 2: Effects on IRES-mediated translation and viral infectivity. Virology 389: 45-58, 2009.

14. Molinaro RJ, Jha BK, Malathi K, Varambally S, Chinnaiyan AM and Silverman $\mathrm{RH}$ : Selection and cloning of poly(rC)-binding protein 2 and Raf kinase inhibitor protein RNA activators of 2',5'-oligoadenylate synthetase from prostate cancer cells. Nucleic Acids Res 34: 6684-6695, 2006.

15. Han W, Xin Z, Zhao Z, Bao W, Lin X, Yin B, Zhao J, Yuan J, Qiang B and Peng X: RNA-binding protein PCBP2 modulates glioma growth by regulating FHL3. J Clin Invest 123: 2103-2118, 2013.

16. Lin X, Yang B, Liu W, Tan X, Wu F, Hu P, Jiang T, Bao Z, Yuan J, Qiang B, et al: Interplay between PCBP2 and miRNA modulates ARHGDIA expression and function in glioma migration and invasion. Oncotarget 7: 19483-19498, 2016.

17. Hu CE, Liu YC, Zhang HD and Huang GJ: The RNA-binding protein PCBP2 facilitates gastric carcinoma growth by targeting miR-34a. Biochem Biophys Res Commun 448: 437-442, 2014.

18. Wan C, Gong C, Zhang H, Hua L, Li X, Chen X, Chen Y, Ding X, $\mathrm{He} \mathrm{S}$, Cao $\mathrm{W}$, et al: $\beta 2$-adrenergic receptor signaling promotes pancreatic ductal adenocarcinoma (PDAC) progression through facilitating PCBP2-dependent c-myc expression. Cancer Lett 373: 67-76, 2016.

19. Fukushi S, Okada M, Kageyama T, Hoshino FB, Nagai $K$ and Katayama $\mathrm{K}$ : Interaction of poly $(\mathrm{rC})$-binding protein 2 with the 5'-terminal stem loop of the hepatitis C-virus genome. Virus Res 73: 67-79, 2001.
20. Tingting $P$, Caiyun F, Zhigang Y, Pengyuan $Y$ and Zhenghong $Y$ : Subproteomic analysis of the cellular proteins associated with the $3^{\prime}$ untranslated region of the hepatitis $\mathrm{C}$ virus genome in human liver cells. Biochem Biophys Res Commun 347: 683-691, 2006.

21. Wang L, Jeng KS and Lai MM: Poly(C)-binding protein 2 interacts with sequences required for viral replication in the hepatitis $\mathrm{C}$ virus (HCV) 5' untranslated region and directs $\mathrm{HCV}$ RNA replication through circularizing the viral genome. J Virol 85: 7954-7964, 2011.

22. Shukla RS, Qin B, Wan YJ and Cheng K: PCBP2 siRNA reverses the alcohol-induced pro-fibrogenic effects in hepatic stellate cells. Pharm Res 28: 3058-3068, 2011.

23. Leidgens S, Bullough KZ, Shi H, Li F, Shakoury-Elizeh M, Yabe T, Subramanian P, Hsu E, Natarajan N, Nandal A, et al: Each member of the poly-r(C)-binding protein 1 (PCBP) family exhibits iron chaperone activity toward ferritin. J Biol Chem 288: 17791-17802, 2013.

24. Wang Y, Wang Y, Xiang J, Ji F, Deng Y, Tang C, Yang S, Xi Q, Liu R and Di W: Knockdown of CRM1 inhibits the nuclear export of p27(Kip1) phosphorylated at serine 10 and plays a role in the pathogenesis of epithelial ovarian cancer. Cancer Lett 343: 6-13, 2014.

25. Wang Y, Liu F, Mao F, Hang Q, Huang X, He S, Wang Y, Cheng C, Wang $\mathrm{H}, \mathrm{Xu} \mathrm{G}$, et al: Interaction with cyclin $\mathrm{H} /$ cyclin-dependent kinase 7 (CCNH/CDK7) stabilizes C-terminal binding protein 2 (CtBP2) and promotes cancer cell migration. J Biol Chem 288: 9028-9034, 2013.

26. Akiba N, Hayakawa I, Keh ES and Watanabe A: Antifungal effects of a tissue conditioner coating agent with $\mathrm{TiO}_{2}$ photocatalyst. J Med Dent Sci 52: 223-227, 2005.

27. Cragg MS and Glennie MJ: Antibody specificity controls in vivo effector mechanisms of anti-CD20 reagents. Blood 103: 2738-2743, 2004.

28. Cheng AL, Kang YK, Chen Z, Tsao CJ, Qin S, Kim JS, Luo R, Feng J, Ye S, Yang TS, et al: Efficacy and safety of sorafenib in patients in the Asia-Pacific region with advanced hepatocellular carcinoma: A phase III randomised, double-blind, placebo-controlled trial. Lancet Oncol 10: 25-34, 2009.

29. Llovet JM, Ricci S, Mazzaferro V, Hilgard P, Gane E, Blanc JF, de Oliveira AC, Santoro A, Raoul JL, Forner A, et al; SHARP Investigators Study Group: Sorafenib in advanced hepatocellular carcinoma. N Engl J Med 359: 378-390, 2008.

30. Okuda K, Ohtsuki T, Obata H, Tomimatsu M, Okazaki N, Hasegawa H, Nakajima Y and Ohnishi K: Natural history of hepatocellular carcinoma and prognosis in relation to treatment. Study of 850 patients. Cancer 56: 918-928, 1985.

31. Rahbari NN, Mehrabi A, Mollberg NM, Müller SA, Koch M, Büchler MW and Weitz J: Hepatocellular carcinoma: Current management and perspectives for the future. Ann Surg 253: 453-469, 2011.

32. Eiring AM, Harb JG, Neviani P, Garton C, Oaks JJ, Spizzo R, Liu S, Schwind S, Santhanam R, Hickey CJ, et al: miR-328 functions as an RNA decoy to modulate hnRNP E2 regulation of mRNA translation in leukemic blasts. Cell 140: 652-665, 2010.

33. Koganti S, Clark C, Zhi J, Li X, Chen EI, Chakrabortty S, Hill ER and Bhaduri-McIntosh S: Cellular STAT3 functions via PCBP2 to restrain Epstein-Barr Virus lytic activation in B lymphocytes. J Virol 89: 5002-5011, 2015.

34. Midorikawa Y, Yamamoto S, Ishikawa S, Kamimura N, Igarashi $\mathrm{H}$, Sugimura $\mathrm{H}$, Makuuchi $\mathrm{M}$ and Aburatani $\mathrm{H}$ : Molecular karyotyping of human hepatocellular carcinoma using single-nucleotide polymorphism arrays. Oncogene 25: 5581-5590, 2006

35. Luo $\mathrm{X}$ and Feng GS: VEGFA genomic amplification tailors treatment of HCCs with sorafenib. Cancer Discov 4: 640-641, 2014. 